\title{
Analisa Usahatani Padi Dengan Sistem Tanam Mesin Rice Transplanter Di Kecamatan Geneng Kabupaten Ngawi (Study Kasus Desa Dempel Kecamatan Geneng Kabupaten Ngawi)
}

\author{
Ratna Mustika Wardhani ${ }^{1}$, Wigik Darsono ${ }^{2}$ \\ ${ }^{1}$ Program Studi Agroteknologi, Universitas Merdeka Madiun, Jl. Serayu No.79, Madiun, 663133 \\ E-mail: ratnamustika@unmer-madiun.ac.id \\ ${ }^{2}$ Program Studi Agroteknologi, Universitas Merdeka Madiun, Jl. Serayu No.79, Madiun, 663133 \\ E-mail: wigikdarsono67@gmail.com
}

\begin{abstract}
Rice is the staple foodstuff in Indonesia, rice consumption in Indonesia has increased every year. The obstacle found in rice production centers is the scarcity of labor, which has become a barrier to rice farming, especially the labor for planting rice seeds. The limited number of workers when planting rice seeds causes the rice planting schedule to not be synchronized. So there needs to be a change in rice farming, one of which is by means of a rice planting system using a rice planting machine, because rice planting machines do not require a lot of labor. Apart from having less labor, the use of rice planting machines also reduces costs. The method used is descriptive, namely research that leads to the disclosure of a problem or situation as it is. The method used is $\Pi=T R-T C(\Pi=$ farm profits $)$ TR $=$ total revenue, and TC $=$ total production costs consisting of fixed costs and variable costs. The results showed that the $R / C$ ratio of rice farming with the machine cropping system was feasible to develop with an $R$ / C ratio of 2.25 .
\end{abstract}

Keywords_-: Farming Analysis; Rice Plants; Rice Transplanter.

\section{PENDAHULUAN}

Padi merupakan bahan pangan pokok bagi masyarakat Indonesia, oleh karena itu komoditas padi memiliki arti strategis baik dari sisi ekonomi, lingkungan hidup, sosial maupun politik. Komoditas padi telah menjadi telah menjadi perhatian pemerintah, khususnya menyangkut masalah produksi, distribusi, pemasaran maupun standarisasi harga domestik agar beras tetap tarsedia sepanjang tahun dengan harga yang cukup tarjangkau. Oleh karena itu dengan pertimbangan aspek teknis dan ekonomis serta urgensinya, pemerintah merumuskan kebijakan swasembada beras secara berkelanjutan. Konsumsi beras di Indonesia pada tahun 2017 dengan jumlah penduduk 240,4 juta jiwa sebesar 27,27 juta ton atau sekitar 113,42 kg/kapita/tahun yang dikonsumsi untuk makanan penduduk dan $71,4 \mathrm{ribu}$ ton atau sekitar $0,30 \mathrm{~kg} / \mathrm{kapita} / \mathrm{tahun}$ digunakan untuk konsumsi non makanan (BPS,2017) kebutuhan beras akan terus meningkat seiring dengan meningkatnya jumlah penduduk di Indonesia. Produksi padi tahun 2017 sebanyak 75,36 juta ton gabah kering giling (GKG) atau mengalami kenaikan sebanyak 4,15 juta ton(6,37\%) dari tahun sebelumnya. Kenaikan produksi tersebut terjadi di pulau jawa sebanyak 2,31 juta ton dan diluar pulau jawa sebanyak 2,21 juta ton (BPS,2017).Namun demikian kebijakan swasembada beras menghadapi tantangan yang semakin kompleks diantaranya adalah : (1) adanya perubahan iklim secara global yang membawa perubahan pada iklim di Indonesia, (2) konversi lahan sawah menjadi lahan non sawah, dan (3) adanya kerusakan pada beberapa jaringan irigasi (Pusluhtan 2012). Kendala lain yang sering dijumpai pada daerah sentra produksi padi dewasa ini adalah tidak tersedianya tenaga kerja usia muda sehingga tenaga kerja menjadi faktor pembatas bagi usahatani padi terutama tenaga kerja untuk kegiatan tanam bibit dan panen kerena kedua kegiatan tersebut memerlukan curahan waktu kerja yang lebih banyak dari kegiatan lainya. Oleh karena itu dengan terbatasnya jumlah tenaga kerja pada saat tanam pindah bibit padi menyebabkan jadwal tanam menjadi tidak serempak yang berdampak pada menurunya produksi padi, kelangkaan tenaga kerja di sektor pertanian mulai terjadi di beberapa daerah sentra produksi padi di jawa timur, terutama pada daerah pertanian yang berdekatan dengan kota besar yang mulai mengalami transformasi menjadi daerah industri. Dengan berkembangnya sektor industri menyebabkan tenaga kerja muda di perdesaan lebih memilih bekerja di sektor industri dibandingkan dengan bekerja dibidang pertanian.

Perubahan atau alih profesi tenaga kerja di perdesaan menyebabkan berkurangnya tenaga kerja sektor pertanian sehingga menimbulkan kelangkaan tenaga kerja. Kelangkaan tenaga kerja pada usaha tani padi lebih dirasakan oleh petani pada saat tanam bibit padi dan pada vase panen karena kedua kegiatan tersebut lebih membutuhkan banyak tenaga kerja diluar keluarga. Walaupun masih ada tenaga kerja dari luar keluarga petani namun jumlahnya masih relatif sdikit dan didominasi oleh para tenaga kerja yang telah berumur lebih dari 40 tahun. Dengan melihat permasalahan tersebut dan fakta dilapangan maka masyarakat desa Dempel Kecamatan Geneng Kabupaten Ngawi berupaya meningkatkan usaha tani padi dengan cara menerapkan pola tanam bibit padi dengan menggunakan mesin tanam padi atau yang sering disebut dengan mesin transplanter. Dengan upaya tersebut diharapkan dapat mengatasi kelangkaan tenaga kerja pada sektor pertanian khususnya para petani Desa Dempel Kecamatan Geneng Kabupaten Ngawi Jawa timur. Selain itu upaya ini juga dapat menekan biaya pengeluaran untuk 
Website : http://agritek.unmermadiun.ac.id/index.php/agritek

tenaga kerja pada vase tanam bibit padi jika dibandingkan dengan polatanam padi cara konvensional. Maka mekanisasi dirasa sangat penting untuk meningkatkan usaha tani padi, karena mekanisasi merupakan introduksi dan penggunaan alat mekanis untuk melaksanakan operasi pertanian. Mekanisasi pertanian sangat diperlukan untuk menuju ke pertanian modern. Menurut Hadiutomo (2012) mekanisasi pertanian dapat lebih efektif dalam mengurangi biaya tenaga kerja dan tujuan mekanisasi yang efektif adalah untuk meningkatkan pendapatan pertanian kecil/rumah tangga petani melalui pengurangan biaya produksi. Maka dari itu hal ini dirasa penting untuk diteliti lebih lanjut. Maka penelitian ini bertujuan untuk mengetahui analisa usahatani padi dengan sistem mesin dan sistem konvensional Di Ngawi khususnya di desa Dempel.

\section{METODE PENELITIAN}

\section{A. Tempat Dan Waktu}

\section{Tempat}

Penentuan daerah penelitian ini dilaksanakan secara sengaja (purposive sampling) yakni di desa Dempel kecamatan Geneng kabupaten Ngawi karena desa dempel telah menerima hibah mesin tanam padi dari kementrian pertanian. Desa Dempel Kecamatan Geneng Kabupaten Ngawi memiliki curah hujan tahunan $2.141 \mathrm{~mm} / \mathrm{tahun}$. Dan kecamatan Geneng berada di 45 mdpl. Berdasarkan tipe iklim menurut (Smitdt Ferguson,1961) menunjukan bahwa sebagian besar kawasan Ngawi memiliki tipe iklim (basah), sebagian kawasan lain memiliki tipe (agak basah), yang meliputi kecamatan Kendal, Gerih,dan Geneng, kawasan lain beriklim (sedang) yang meliputi Kecamatan Sine, Kwadungan, Pangkur, Karangjati, Bringin dan Padas. Desa Dempel termasuk kedalam iklim yang agak basah dengan suhu rata-rata tahunan berkisar antara $23,0^{\circ} \mathrm{C}-33,0^{\circ} \mathrm{C}$, sedangkan kelembaban udara bervariasi antara $60 \%$ hingga $94 \%$ (Smith Ferguson, 1961).

\section{Waktu}

Penelitian ini dilaksanakan pada bulan April sampai dengan bulan Juni 2018.

\section{B. Metode Pengambilan Sampel}

\section{Sampel penelitian}

Pengambilan sampel dalam penelitian ini diawali dengan penentuan lokasi daerah penelitian dilakukan secara sengaja (purpose sampling). Selanjutnya dari desa yang terpilih diambil sample responden secara acak (random sampling) untuk memastikan bahwa segmen dari populasi dapat terwakili dalam sample, sebanyak 10 persen dari populasi yang ada. Menginggat bahwa petani yang menanam padi dengan mesin tanam kurang dari seratus orang maka dilakukan sampling dengan prosedur pengambilan merujuk prosedur yang dikemukakan oleh Arikunto (2006), apabila populasi sama lebih dari seratus orang, dapat diambil sampel sebanyak antara $10-25 \%$ dan apabila populasi sama atau kurang dari seratus orang harus diambil semua. Berdasarkan pertimbangan tersebut, dalam penelitian ini dari 719 petani padi di Desa Dempel ada 25 petani yang menggunakan mesin tanam padi yang tersebar di 7 dusun maka dari 25 responden semua ditetapkan menjadi sepel penelitian dan untuk pembanding maka diambil 25 responden yang menanam padi secara konvensional secara acak dari 7 dusun dari Desa dempel masing- dusun diambil 5 responden sehingga jumlah sampel penelitian 25 untuk responden petani yang menggunakan mesin tanam dan 25 responden untuk petani tanam konvensional (Arikunto, 2006).

\section{Cara Pengumpulan Data}

\section{Tenik Wawancara}

Wawancara adalah tanya jawab antara peneliti dengan petani untuk memperoleh data-data yang diperlukan berdasarkan jawaban jawaban langsung dari petani.

\section{Teknik Pencatatan}

Pencatatan adalah cara memperoleh data dengan mencatat data dari berbagai instansi dari tingkat desa sampai ke petani- petani yang didasarkan atas laporan serta catatan yang ada, dan hasil merupakan data sekunder.

\section{Teknik Observasi}

Observasi adalah cara pengumpulan data tanpa mengajukan pertanyaan-pertanyaan tetapi dengan jalan mengamati obyek yang diteliti. Observasi di sini bertujuan mencocokan data yang diperoleh dari hasil wawancara dengan keadaan sebelumnya dan dapat dipergunakan untuk melengkapi data yang ada.

\section{Sumber Data}

Data primer yaitu data yang diperoleh langsung dari responden atau petani. Alat bantu yang digunakan adalah kuisioner atau pertanyaan-pertanyaan yang diajukan pada responden. 
Website : http://agritek.unmermadiun.ac.id/index.php/agritek

Data sekunder yaitu data terdokumentasi yang relevan yang dapat diperoleh dari berbagai sumber yang dipercaya dan dapat dipertanggung jawabkan mulai dari tingkat desa sampai ke petani-petani.

\section{E. Metode analisa}

Metode yang digunakan dalam penelitian ini adalah metode deskriptif, yaitu metode yang mengarah pada pengungkapan suatu masalah atau keadaan sebagaimana adanya dan mengungkapkan fakta-fakta yang ada. Penelitian deskriptif perlu menciptakan konsep-konsep ilmiah, sekaligus berfungsi dalam mengadakan suatu spesifikasi mengenai gejala-gejala fisik maupu sosial yang dipersoalkan. Hasil penelitianya memberikan gambaran objek yang diteliti (moh, pabunda,2005) data yang dikumpulkan mula-mula disusun, dijelaskan, dianalisis dan selajutnya disimpulkan. Jenis analisis yang digunakan adalah:

\section{F. Analisa Pendapatan}

Untuk menganalisa usahatani padi dengan pola tanam mesin dan konvensional pada penelitian ini dilakukan analisis tabulasi selanjutnya dilakukan persamaan sebagai berikut menurut soekartawi (1995), untuk menghitung pendapatan dalam usahatani dapat dihitung dengan rumus :

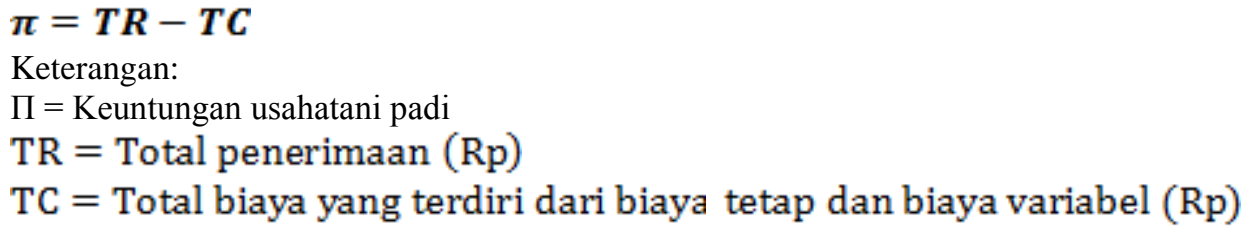

$\mathrm{R} / \mathrm{C}$ Rasio $=T R / T C$

Keterangan :

- Jika $\mathrm{R} / \mathrm{C}<1$ maka usahatani padi yang dilakukan secara ekonomi belum menguntungkan dan tidak layak digunakan.

- Jika R/C >1 maka usahatani padi yang dilakukan secara ekonomi menguntungkan dan layak untuk digunakan.

\section{G. Konsep pengukuran variabel}

1. Biaya yaitu keseluruhan dana yang dikeluarkan oleh petani dalam menghasilkan padi/gabah dalam satu kali panen yang diukur dengan satuan rupiah $(\mathrm{Rp})$

a) Biaya tetap, yang terdiri dari biaya sewa lahan dan penyusutan alat-alat yang digunakan dalam usahatani.

b) Biaya variabel yang terdiri dari biaya bibit, pupuk, obat-obatan, pengairan, dan biaya tenaga kerja.

2. Produk, yaitu banyaknya padi yang dihasilkan oleh petani dalam satu musim tanam diukur dengan satuan (kg)

3. Pendapatan yaitu keseluruhan penerimaan dari hasil penjualan padi setelah dikurangi dengan biaya-biaya usahatani, yang dinyatakan dalam satuan (Rp)

4. Penerimaan yaitu sejumlah uang yang diterima oleh petani dari hasil penjualan padi dalam satu musim panen yang diukur dalam satuan rupiah $(\mathrm{Rp})$.

\section{III.HASIL DAN PEMBAHASAN}

\section{A. Gambaran Umum Lokasi Penelitian}

Desa Dempel secara atministratif terletak di kecamatan Geneng, kabupaten Ngawi, propinsi Jawa Timur. Luas wilayah desa Dempel dengan luas wilayah 447.293 ha.

Batas wilayah Desa Dempel Kecamatan Geneng Kabupaten Ngawi sebagai berikut :

1. Sebelah utara : berbatasan dengan desa kersoharjo

2. Sebelah timur : berbatasan dengan sungai Madiun

3. Sebelah selatan : berbatasan dengan Desa Kersikan

4. Sebelah barat : berbatasan dengan Jalan Raya Ngawi - Madiun dan berbatasan dengan Desa Klitik a. Jarak desa :

Dengan kantor Kabupaten Ngawi

Lama tempuh

Dengan Kecamatan Geneng

Lama tempuh

$$
\begin{aligned}
& : \pm 17,0 \mathrm{KM} \\
& : \pm 31 \mathrm{Menit} \\
& : \pm 7,6 \mathrm{KM} \\
& : \pm 13 \text { Menit }
\end{aligned}
$$

Bentuk permukaan tanah: Dataran Rendah
b. Produktivitas tanah
: Baik
c. Jumlah RT
:26 RT
d. Jumlah RW
: $7 \mathrm{RW}$ 


\section{Website : http://agritek.unmermadiun.ac.id/index.php/agritek}

\section{B. Kondisi Monografi}

1. Jumlah penduduk Desa Dempel menurut pendataan yang dilakukan : \pm 4452

2. Komposisi penduduk Desa Dempel Kecamatan Geneng Kabupaten Ngawi berdasarkan jenis kelamin adalah 2153 orang berjenis kelamin laki-laki dengan persentase 47,2\% dan 2299 orang berjenis kelamin perempuan dengan persentase $52,7 \%$ dengan jumlah total keseluruhan adalah 4452 orang dengan persentase $100 \%$ (Data profil Desa Dempel 2017).

Desa Dempel memiliki luas wilayah sebesar 447.293 ha. Wilayah ini berada di 45- $900 \mathrm{~m}$ di atas permukaan air laut. Curah hujan di desa Dempel Kecamatan Geneng Kabupaten Ngawi mencapai $2.141 \mathrm{~mm} /$ tahun. Strata (jenis iklim) menurut termasuk strata jenis iklim B (Anonymous,2012).

Usahatani di desa Dempel merupakan mata pencaharian utama bagi sebagian besar masyarakat desa Dempel. Data yang tercatat di profil desa Dempel pada tahun 2017 sebanyak 719 orang berprofesi sebagai petani dari jumlah penduduk sebanyak 3416 orang. Wilayah desa Dempel memiliki iklim tropis sehingga sangat bagus sekali untuk dijadikan lahan pertanian terutama tanaman palawijo dan tanaman pangan termasuk tanaman padi. Tanaman padi yang dapat ditanam 3 musim tanam di desa ini menjadikan Desa Dempel sangat potensial untuk usahatani padi kerena padi di Desa Dempel dapat ditanam setiap musim.

Tabel 1.

Karakteristik petani padi tanam mesin dan konvensional desa Dempel 2018

\begin{tabular}{|c|c|c|c|c|c|c|}
\hline \multirow{2}{*}{ No } & \multirow{2}{*}{ Karakteristik } & \multirow{2}{*}{ Kategori } & \multirow{2}{*}{$\begin{array}{c}\text { Petani } \\
\text { T.mesin }\end{array}$} & \multirow{2}{*}{$\begin{array}{c}\text { Petani } \\
\text { kvsional }\end{array}$} & \multicolumn{2}{|c|}{ Persen\% } \\
\hline & & & & & T.mesin & Kvsional \\
\hline \multirow{3}{*}{1} & \multirow{3}{*}{ Umur petani } & $\begin{array}{l}\text { Muda } \\
(25-50)\end{array}$ & 25 & 18 & $100 \%$ & $72 \%$ \\
\hline & & $\begin{array}{c}\text { Tua } \\
(51-80)\end{array}$ & 0 & 7 & $0 \%$ & $28 \%$ \\
\hline & & Jumlah & 25 & 25 & $100 \%$ & $100 \%$ \\
\hline \multirow{6}{*}{2} & \multirow{6}{*}{$\begin{array}{l}\text { Tk pen } \\
\text { didikan petani }\end{array}$} & $\begin{array}{c}\text { Tidak } \\
\text { sekolah }\end{array}$ & 0 & 3 & $0 \%$ & $12 \%$ \\
\hline & & SD & 7 & 13 & $28 \%$ & $52 \%$ \\
\hline & & SMP & 3 & 4 & $12 \%$ & $16 \%$ \\
\hline & & SMA & 7 & 3 & $28 \%$ & $12 \%$ \\
\hline & & S1 & 6 & 0 & $24 \%$ & $0 \%$ \\
\hline & & Jumlah & 25 & 25 & $100 \%$ & $100 \%$ \\
\hline \multirow{3}{*}{3} & \multirow{3}{*}{ Luas lahan } & $<5000 \mathrm{~m}^{2}$ & 19 & 16 & $76 \%$ & $64 \%$ \\
\hline & & $>5000 \mathrm{~m}^{2}$ & 6 & 9 & $24 \%$ & $39 \%$ \\
\hline & & Jumlah & 25 & 25 & $100 \%$ & $100 \%$ \\
\hline \multirow{3}{*}{4} & \multirow{3}{*}{ Status lahan } & Sewa & 3 & 2 & $12 \%$ & $8 \%$ \\
\hline & & Pribadi & 22 & 23 & $88 \%$ & $92 \%$ \\
\hline & & Jumlah & 25 & 25 & $100 \%$ & $100 \%$ \\
\hline \multirow{3}{*}{5} & \multirow{3}{*}{$\begin{array}{l}\text { Tanggungan } \\
\text { klrg petani }\end{array}$} & 1 - 4 Orang & 23 & 23 & $92 \%$ & $92 \%$ \\
\hline & & $>4$ orang & 2 & 2 & $8 \%$ & $8 \%$ \\
\hline & & Jumlah & 25 & 25 & $100 \%$ & $100 \%$ \\
\hline
\end{tabular}

\section{Analisis Biaya Usahatani Padi}

Analisa mengenai biaya produksi usahatani padi dengan pola tanam mesin di Desa Dempel Kecamatan Geneng Kabupaten Ngawi dapat dilihat pada tabel 2. Berikut :

Tabel 2.

Rata-rata biaya usahatani.

\begin{tabular}{cccc}
\hline \multirow{2}{*}{ No } & \multirow{2}{*}{ Uraian } & \multicolumn{2}{c}{ Biaya Usahatani (Rp) } \\
\cline { 3 - 4 } & & Tanam Mesin & Konvensional \\
\hline 1 & $\begin{array}{l}\text { Biaya Variabel } \\
\text { a. Bibit }\end{array}$ & 286,000 & 384,400
\end{tabular}


Website : http://agritek.unmermadiun.ac.id/index.php/agritek

\begin{tabular}{lcc} 
b. Pupuk & 645,000 & 666,008 \\
c. Obat-obatan & 603,280 & 596,280 \\
d. Tenaga kerja & $3,989,548$ & $4,203,376$ \\
e. Pengairan & 473,800 & 949,660 \\
\hline Sub Total & $5,997,628$ & $6,779,724$ \\
\hline 2 & & \\
Biaya Tetap & 240,000 & 740,000 \\
$\begin{array}{l}\text { a. Sharing } \\
\text { b. Penyusutan } \\
\text { Alat }\end{array}$ & $1,289,100$ & 701,000 \\
\hline Sub Total & $1,529,100$ & $1,441,000$ \\
\hline Total Biaya & $\mathbf{7 , 5 2 6 , 7 2 8}$ & $\mathbf{8 , 2 2 0 , 7 2 4}$ \\
\hline Usahatani & : Analisis Data Primer, 2018
\end{tabular}

Berdasarkan analisis biaya usahatani padi sawah dengan sistem tanam menggunakan mesin Transplanter dan sistem tanam konvensional menunjukan ada selisih jumlah biaya usahatani yang dikeluarkan oleh petani dalam menjalankan usahataninya tersebut. Total biaya usahatani yang dikeluarkan oleh petani padi dengan sistem pola tanam menggunakan mesin tanam sebanyak Rp 7,526,728 biaya tersebut lebih sedikit dibandingkan dengan biaya usahatani padi dengan sistem konvensional yang jumlahnya sebanyak Rp 8,220,724 yang jauh lebih besar nilainya jika dibandingkan dengan biaya usahatani padi dengan sistem tanam mesin seperti yang ditujukan pada tabel 2 di atas. Biaya-biaya usahatani tersebut meliputi biaya variabel dan biaya tetap.

\section{Analisis Penerimaan, Pendapatan dan R/C Rasio Usahatani padi}

Untuk mengetahui kelayakan usahatani padi dengan pola tanam mesin dan sistem tanam konvensional dapat diketahui dengan melihat total biaya produksi, volume produksi, harga jual, penerimaan dan pendapatan yang diperoleh petani. Total penerimaan, pendapatan dan $\mathrm{R} / \mathrm{C}$ rasio usahatani padi tanam mesin dapat dilihat pada tabel 4 berikut :

Tabel 4.

Rata-rata penerimaan, Pendapatan dan R/C Rasio usahatani padi.

\begin{tabular}{|c|l|c|c|}
\hline No & \multicolumn{1}{|c|}{ Uraian } & $\begin{array}{c}\text { Tanam } \\
\text { Mesin }\end{array}$ & $\begin{array}{l}\text { Tanam } \\
\text { Konvensional }\end{array}$ \\
\hline 1 & Volume Produksi & & \\
\hline & a. Padi/Gabah $(\mathrm{kg})$ & 3683,8 & 3585,6 \\
\hline 2 & Harga Jual & & 4,600 \\
\hline & a. Padi/kg (Rp) & 4,600 & $16,493,760$ \\
\hline 3 & Total Penerimaan (Rp) & $16,945,480$ & $8,220,724$ \\
\hline 4 & $\begin{array}{l}\text { Total Biaya Produksi } \\
\text { (Rp) }\end{array}$ & $7,526,728$ & $8,273,036$ \\
\hline 5 & Total Pendapatan (Rp) & $9,418,752$ & $\mathbf{1 . 9 9}$ \\
\hline 6 & R/C Rasio & $\mathbf{2 , 2 5}$ & Sumber : Analisis Data Primer.2018 \\
\hline \multicolumn{4}{|c|}{}
\end{tabular}

Produk pertanian yang dihasilkan petani padi teknik tanam mesin adalah berupa gabah. Untuk harga gabah pada musim tanam ke 2 atau musim gadu adalah Rp 4,600 / kg. harga sekian dirasa masih bagus oleh petani jika dibanding musim gadu sebelumnya, hal ini juga dikarenakan kualitas padi atau gabah yang dihasilkan pada musim ini sangat bagus karena kadar airnya sangat rendah. Produksi gabah sebesar 3683,8 kg dengan harga jual Rp 4,600 dari penjualan tersebut petani akan menghasilkan uang sebesar Rp 16.945.480 kemudian dari penerimaan yang sebesar Rp 16.945.480 tersebut akan dikurangi total biaya usahatani yang dikeluarkan oleh petani untuk proses usahataninya sebesar Rp 7.526.728. Dan ketemulah pendapatan bersih petani sebesar Rp 9.418.752.

$\mathrm{R} / \mathrm{C}$ rasio merupakan perbandingan antara total penerimaan dengan total biaya produksi. Nilai R/C rasio usahatani petani padi dengan teknik pola tanam mesin pada musim tanam padi ke 2 atau musim gadu sebesar 2,25. Nilai R/C >1 atau nilai R/C lebih dari satu maka usahatani padi dengan sistem tanam mesin yang dilakukan oleh petani dapat dikatakan secara ekonomi menguntungkan dan layak untuk dikembangkan karena pendapatan petani bernilai lebih besar dibandingkan dengan total biaya produksi yang dikeluarkan (Nasrudin, 2000).

Produk pertanian yang dihasilkan oleh petani padi dengan sistem pola tanam konvensional adalah berupa gabah. Untuk harga gabah pada saat musim tanam padi ke 2 atau musim gadu sebesar Rp 4,600/kg. harga sekian dirasa masih bagus oleh petani jika dibandingkan dengan harga gabah pada musim gadu yang sebelumnya, hal ini juga dikarenakan kualian padi atau gabah yang diproduksi petani pada musim ini kualitasnya cukup bagus karena kadar airnya sangat rendah. Produksi padi atau gabah 
Website : http://agritek.unmermadiun.ac.id/index.php/agritek

yang dihasilkan petani sebesar 3585,6 kg dengan harga jual $\mathrm{Rp}$ 4,600 dari penjualan gabah tersebut petani akan menerima uang hasil penjualan gabah sebesar Rp 16.493.760 kemudian dari total penerimaan yang diterima petani dari hasil penjualan gabah tersebut dikurangi dengan total biaya produksi yang dikeluarkan oleh petani untuk usahataninya sebesar Rp 8.220 .724 dan ketemulah pendapatan bersih petani sebesar Rp 8.273.036.

$\mathrm{R} / \mathrm{C}$ rasio merupakan perbandingan antara total penerimaan dengan total biaya produksi. Nilai $\mathrm{R} / \mathrm{C}$ rasio usahatani padi dengan sistem pola tanam konvensional pada musim tanam padi ke 2 atau musim gadu sebesar 1,99 . Nilai R/C > 1 atau nilai R/C lebih dari satu maka usahatani padi dengan sistem pola tanam konvensional yang dilakukan oleh petani dapat dikatakan secara ekonomi menguntungkan dan layak untuk dikembangkan karena pendapatan petani bernilai lebih besar dibandingkan dengan total biaya produksi yang dikeluarkan oleh petani (Nasrudin,2000).

\section{IV.KESIMPULAN}

Berdasarkan hasil penelitian yang telah dilakukan di Desa Dempel Kecamatan Geneng Kabupaten Ngawi dapat di simpulkan sebagai berikut :

Petani dengan dengan sistem tanam mesin dalam usahataninya lebih menguntungkan,dengan produksi sebesar $3683,8 \mathrm{~kg}$ dengan pendapatan sebesar Rp 9.418.752 nilai R/C rasio sebesar 2.25 lebih besar jika dibandingkan dengan usahatani padi tanam konvensional dengan produksi 3585,6 kg besar pendapatan Rp 8.273.036, dengan nilai R/C rasio sebesar 1,99, maka secara ekonomi usahatani padi tanam mesin dan konvensional dinyatakan layak untuk dikembangkan.

\section{UCAPAN TERIMAKASIH}

Ucapan terima kasih yang tidak terhingga disampaikan kepada Rektor Universitas Merdeka Madiun yang telah memberikan kesempatan dalam pelaksanaan penelitian ini dan juga kepada keluarga dan teman-teman yang telah memberi dukungan sehingga terlesaikan penelitian ini.

\section{DAFTAR PUSTAKA}

Anonymous, 2012. Green Education Centre. http:// budidaya-padi.html. Diakses tanggal 30 Juni 2018.

Anonim, 2013. Mekanisasi Dalam Pertanian Padi URL http:/mekanisasi sulpirahim. blogspot.com /2013 05 archive.html. diunduh tanggal 18 Agustus 2018

Atman. 2009. Respon Padi Sawah Batang Lembang Terhadap Umur Bibit. Jurnal Ilmiah Tambua, 8 (2) : 239 - 242.

Arikunto, Suharsimi, 2006. Prosedur Penelitian Suatu Pendekatan Praktek, Rineke Cipta, Jakarta.

BPS, 2017. Produksi Padi, Jagung, dan Kedelai. Angka Sementara Tahun 2015.Badan Pusat Statistik. No. 28/03/Th. XIX, 1 Maret 2016. Diakses dari(http://www.bps.go.id) pada tanggal 28 Juni 2018.

Ferguson, S. T, 1961, Rules For Rejection of Outliers, University of California at Los Angeles.

Hadiutomo, K. 2012. Mekanisasi Pertanian. IPB Press. Bogor. $457 \mathrm{Hal}$.

Hasanah, I. 2007. Bercocok Tanam Padi. Azka Mulia Media. Jakarta. 68 hal.

Herawati, W. D. 2012. Budidaya Padi. Javalitera. Jogjakarta. 100 hal.

Hermanto. 1996. Analisa Usahatani. Bina Aksara. Jakarta

Halle, F., Oldeman, R.A.A., dan P.B Thomlinson. 1978. Tropical Trees and Forest. Springer-Verlag. Berlin Hedelberg. New York.

Kuipers, H .dan L. Kowenhopn. 1983. Pengolahan Tanah; Aplikasi Pengukuran Lapangan. Agricultural University Wageningen-Brawijaya University. Malang.

Masdar. 2006. Pengaruh Jumlah Bibit Per Titik Tanam dan Umur Bibit TerhadapPertumbuhan Reproduktif Tanaman Padi Pada Irigasi TanpaPenggenangan. Jurnal Dinamika Pertanian, 21 (2) : 121-126

M. Taufik, (2010). Inovasi Pendidikan Melalui Problem Based Learning: Pendidik Memberdayakan Pembelajaran di Era Pengetahuan.Bagiamana Jakarta: Prenada Media Group

Muliasari, A. A. 2009. Optimasi Jarak Tanam dan Umur Bibit pada Padi Sawah.

Moh. Pabunda Tika. 2005. Metode Penelitian Geografi. Jakarta: PT. Bumi Aksara.

Nasrudin, Endin. 2010. Psikologi Manajemen. Bandung: CV Pustaka Setia.

Pabunda,T. 2005. Metode Penelitian Geografi. Jakarta: Bumi Aksara

Rosmawati, D.Y. 2008. Pengaruh Tinggi Genangan terhadap Pertumbuhan Gulma danProduksi Padi Hibrida (Oryza sativa L.). Skripsi. Fak. Pertanian IPB. Bogor. pp: 12-28

Unadi, A. dan Suparlan. 2011. Dukungan Teknologi Pertanian Untuk Industrialisasi Agribisnis Pedesaan. Makalah Seminar Nasional Penyuluhan Pertanian Pada Kegiatan Soropadan Agro Expo Tanggal 23Agustus 2018. BalaiBesar Pengembangan Mekanisasi Pertanian, Bogor.

Suratiyah, Ken. 2006. Ilmu Usahatani. Penebar Swadaya. Jakarta.

Sudirman, S. P. dan A. Iwan. S., 1994. Mina Padi Budi Daya Ikan Bersama Padi.Penebar Swadaya. Jakarta. 73 hal.

Surowinoto, S. 1982. Budidaya Tanaman Padi. Jurusan Agronomi Faperta IPB. Bogor. Hal: 56-58.

Soekartawi. 2003. Agribisnis Teori dan Aplikasinya. Penerbit PT Raja Grafindo Persada, Jakarta.

Witjaksono, R. 1990. Hubungan Perilaku Komunikasi dan Tingkat Pemahama Informasi Anggota Kelompok Tani Tentang Paket Teknologi Supra Insus di WKBPP Sanden, Kabupaten Bantul, D.I. Yogyakarta. Pascasarjana IPB. Bogor. 